\title{
Exercícios Ambulatórios para uma Reflexão acerca das Psicologias Sociais e da Cidade*
}

\author{
Rodrigo Lages e Silva ${ }^{1}$ \\ ${ }^{1}$ Universidade Federal do Rio Grande do Sul, RS, Brasil.
}

\begin{abstract}
Resumo: Penso a relação entre diferentes psicologias sociais e as cidades. Para tanto, caracterizo tais psicologias como manifestantes que foram às ruas em 2013 nas chamadas "jornadas de junho". Faço, a partir desse experimento ficcional, uma reflexão acerca do compromisso ético e dos desafios práticos e epistêmicos que as psicologias sociais enfrentam em diferentes campos empíricos, tais como: a luta por direitos humanos; as políticas públicas; a prática científica e acadêmica; e os movimentos sociais. Neste processo, destaca-se a cidade em sua radical heterogênese como potência de desacomodação das formações estereotipadas que assombram as práticas e as pesquisas em Psicologia Social. Por fim, este texto relaciona estas reflexões com a temática do Encontro Regional Sul da ABRAPSO de 2014, em Londrina, que foi "O clamor das ruas", problematizando a dialética rua $\mathrm{x}$ interioridade que é constituinte da subjetividade contemporânea, com vistas à problematização de uma dimensão comum que tem na cidade seu modo de expressão por excelência.
\end{abstract}

Palavras-chave: Psicologia Social. Jornadas de junho. Cidade. Rua. Subjetividade.

\section{Ambulatory Exercises for a Reflection upon Social Psychologies and the City}

\begin{abstract}
I think on the relation between different social psychologies and the cities. In order to do that, I figure those social psychologies as demonstrators who took the streets in the so -called June Journeys in 2013. From this fictional experiment I make a reflection about the ethical engagement and the practical and epistemic challenges faced by social psychologies in different empirical fields: human rights struggle; public policies; scientific and academy practices; and social movements. By doing so, the city in its radical hetero engenderment is highlighted as a potential inconvenience to the stereotyped formations that haunts Social Psychology in praxis and research. By the end, this text relates those reflections with the theme from de Regional South Encounter of ABRAPSO in 2014, at Londrina, "The claim from the streets", questioning the dialectics street $\mathrm{x}$ interior which is constitutive of the contemporary subjectivity, in order to analyse a common dimension which has in the city its expression par excellence.
\end{abstract}

Keywords: Social Psychology. June Journeys. City. Street. Subjectivity. 


\title{
Ejercicios Ambulatorios para una Reflexión acerca de las Psicologías Sociales y Urbanas
}

\begin{abstract}
Resumen: Pienso acerca de la relación de las distintas psicologías sociales y las ciudades. En este objetivo caracterizo estas distintas psicologías sociales como manifestantes que salieron a las calles en las llamadas "días de junio" en 2013. Pienso en la relación entre diferentes psicologías sociales y ciudades. Con este fin, caracterizo tales psicologías como manifestantes que salieron a las calles en 2013 en los llamados "viajes de junio". A partir de este experimento ficticio, reflexiono sobre el compromiso ético y los desafíos prácticos y epistémicos que enfrentan las psicologías sociales en diferentes campos empíricos, tales como: la lucha por los derechos humanos; políticas públicas; práctica científica y académica; y movimientos sociales. En este proceso, la ciudad se destaca en su heterogénesis radical como un poder desencadenante de formaciones estereotipadas que persiguen las prácticas e investigaciones de la Psicología Social. Finalmente, este texto relaciona estas reflexiones con el tema de la Reunión Regional del Sur ABRAPSO 2014 en Londrina, que fue "El clamor de las calles", problematizando la dialéctica calle $\mathrm{x}$ interioridad que es un componente de la subjetividad contemporánea, con miras a problematizar una dimensión común que tiene en la ciudad su modo de expresión por excelencia.
\end{abstract}

Palabras clave: Psicología Social. Jornadas de junio. Ciudad. Calle. Subjetividad.

\section{Apresentação}

Os estudos em Psicologia Social no Brasil e, consequentemente, a formação em Psicologia Social já orbitaram ao redor do binário: ciência ou política, o qual não apenas marcou a Psicologia Social brasileira, como ensejou a criação da Associação Brasileira de Psicologia Social-ABRAPSO (Almeida, 2012). Entre os assuntos de um saber ou de uma verdade independente dos povos (ciências) ou de uma gestão dos povos descompromissada com a verdade porque comprometida com sua visão de mundo (política), o campo da Psicologia Social foi-se organizando em um polo dito científico ou experimental (Rodrigues, 1979), oriundo das ciências exatas e tecnológicas; e o campo da Psicologia Social de tradição crítica, que consolidou-se (Lane, 1984) em práticas comunitárias, intervenções grupais, laborais, educacionais, em geral sob a ótica da autonomia e da emancipação dos coletivos.

Num certo sentido, pode-se dizer que a segunda perspectiva prevaleceu, de modo que os psicólogos sociais estão cada vez mais inseridos em práticas governamentais, dentro ou fora da estrutura formal do Estado. E a pesquisa e o ensino em Psicologia Social também se vem orientando em grande parte por legislações, normativas e estratégias de atuação previstas em grandes políticas públicas nacionais tais como o Sistema Único de Saúde (SUS), o Sistema Único de Assistência Social (SUAS), o Sistema Nacional de Atendimento Socioeducativo (Sinase), as diretrizes para o trabalho em doenças sexualmente transmissíveis (DST) /AIDS, redução de danos, e uma série de outras políticas públicas que orientam o trabalho do psicólogo no campo. Estas estratégias governamentais vem sendo objeto de pesquisas acadêmicas e frequentam os cursos de graduação de psicólogos em geral nas disciplinas de Psicologia Social, Psicologia Comunitária, Psicologia e Políticas Públicas, Psicologia Institucional etc.

A pergunta que move este ensaio, nesse contexto, é a seguinte: quando a Psicologia Social se vê tão envolvida com a construção e a execução de políticas públicas, aquele sentido político que apontava para uma potência de transgressão do instituído e/ou de emancipação dos coletivos ainda é possível? Será que a Psicologia Social pode ou deve se sentir confortável dentro das políticas públicas?

Para percorrer essa indagação, aposto na cidade e sua radical heterogeneidade como potência de interpelação da Psicologia Social e como estratégia para fazê-la mais articulada com a perspectiva emancipatória e transgressora que marcou o giro epistemo- 
lógico da Psicologia Social brasileira a partir de sua perspectiva crítica.

\section{A cidade}

Num texto que já tem mais de duas décadas, Décio Pignatari (1995), o grande semiólogo brasileiro e poeta concreto escreveu: "A cidade é uma mensagem que nem todos entendem, mas que todos são obrigados a ler" (p. 205). Sensível às transformações em curso nos modos de produção do urbano, Pignatari apontava um efeito de usuariedade que se vinha sobrescrevendo aos os modos de vida na cidade. Ao invés de a cidade inspirar novas sensibilidades sobre a experiência da vida comum, a semiótica da expansão imobiliária, dos fluxos automotivos, da objetivação carcerária da cidade - sempre zoneando riscos e intensificando vigilâncias - tinha como efeito a organização das vidas urbanas como experiências de sobrevivências de curto prazo, nas quais a cidade é utilizada (daí o termo usuariedade) como meio para obtenção de recursos e satisfação de necessidades, e não como matéria de expressão de sentidos ou amplificação de potências. Experimentada enquanto plano de deslocamento e coleta de itens de recompensa (trabalho, objetos de consumo, encontros amorosos etc.), a cidade estaria sendo apartada da sua força semiótica mais potente, qual seja, a de fazer e desfazer sentidos para os vívidos: corporais, perceptivos, sensíveis, sensuais, coletivos etc.; para o que Pignatari chamou, simplesmente, de dimensão política ou comunitária e que prefiro chamar de plano comum.

Em outro texto com mote parecido, Michel de Certeau (1994) descreve a experiência de viajar de trem como uma "experiência especulativa do mundo" (p. 194). Isolado na cabine, o passageiro do trem é conduzido a supor-se numa estase, em contraposição ao mundo veloz que se descortina pela janela. Nem o passageiro e nem o mundo são estáticos. Mas os trilhos do trem e a janela produzem o truque que permite a experiência de interioridade. A modulação cinética do trem induz à experiência da estase interior, de uma subjetividade unitária e definível em contraposição ao mundo borrado e efêmero que passa "lá fora". Apenas os estalidos dos trilhos e das vidraças a se rebaterem nos caixilhos é que vão denunciar o grande artesão desse truque: $o$ motor da locomotiva.

O que estas passagens nos mostram é a experiência não ingênua do olhar e do transitar. Andar pela cidade, habitar, deslocar-se nada tem de natural ou necessário, mas são ações moduladas a partir de lógicas que por vezes nos escapam ou não sabemos ler, como nos adverte Pignatari. Olhar o mundo através de janelas ou de telas, "tudo em quadrados" como na música de Adriana Calcanhotto (2002), não apenas seleciona ou recorta aquilo que se vê, mas também modifica o modo de olhar, cria a ilusão de interioridade, a ficção da distância, "remoto controle". Modulações, pois, do transitar e do ver que se expressam em práticas de si e em condução das condutas próprias e alheias, ou seja, em governamentalidades (Foucault, 1979). No governo de si e no dos outros. Na produção do si próprio em relação com os outros e na precaução relativamente aos usos que os outros fazem do seu potencial de variação ou de diferenciação, de sua "liberdade". Um conjunto de práticas, portanto, que também chamamos de gestão, cuidado ou intervenção e que incidem não apenas sobre os corpos, mas, na contemporaneidade, têm foco, sobretudo, nos espaços em que transitamos e nos objetos que emergem desses regimes de visibilidade.

Tais práticas vêm produzindo um efeito asfixiante ou carcerário de habitar a cidade. Tanto do ponto de vista de uma racionalidade urbanizadora, quanto das práticas cotidianas, ínfimas, de viver a cidade, há uma tendência de condução da cidade para um comportamento que Landa (2000) chamou de cidade como “capital”, por oposição à cidade como "metrópole".

Centros metropolitanos exerceram sua influência através das fronteiras internacionais, enquanto as capitais eram guardiãs e protetoras dessas fronteiras e dos territórios que elas reuniam. Portanto, enquanto o território da primeira se expandia através do mar, a última era frequentemente fechada em sua terra, conectada com as regiões interiores. Capitais tendem a estabelecer restrições aos fluxos de trocas, e usam taxas, pedágios e tarifas para extrair energia desses circuitos; as metrópoles, ao contrário, tendem a libertar esses fluxos de todos os obstáculos, buscando explorar as periferias mais distantes mais integralmente. (Nós temos dois tipos diferentes de poder: o imperialismo xenofóbico, nacionalista e o imperialismo de água salgada). No período de formação das nações-estado: Paris, Madrid, Bagdá e Pequim, eram exemplos perfeitos de capitais nacionais; enquanto Veneza, Gênova, Córdoba 
e Cantão tipificavam as metrópoles marítimas. Cidades como Londres, eram uma mistura dos dois tipos (Landa, 2000, p. 50)

Há momentos na história das cidades em que dentro da própria dinâmica urbana engendra-se uma Babel sem torre, isto é, em que há uma convergência de trabalho e de esforços para a construção de um enorme projeto urbano que não é o de uma obra determinada, mas o da cidade como um todo. Essa expansão urbana dispara fluxos e encontros que excedem os ideais de planejamento ou as intenções finais. As ruas passam a acolher línguas e sotaques distintos, religiões não oficiais, aromas e comidas exóticas. Um conceito de beleza e de pureza é abalado. Por isso, levando essa diferenciação entre capital e metrópole proposta por Landa (2000) para além das diferenças arquitetônicas ou funcionais que ela enuncia, pode-se dizer que mesmo antes do surgimento da noção de metrópole para se referir à dinâmica urbana engendrada pelo colonialismo, já se poderiam supor devires metropolitanos, ou melhor, que devires metropolitanos habitam as cidades, antes, durante e depois do colonialismo.

Seja a criação da Roma Imperial, a Europa dos descobrimentos ou o milagre financeiro brasileiro durante os anos 1960, períodos de mudanças bruscas e expansivas na economia geram crescimento urbano e movimentos migratórios intensos. No primeiro caso, o da Roma antiga, deu-se uma passagem da cidade-Estado para capital de Império e uma mudança tanto das técnicas e dos princípios de construção civil, quanto da sociabilidade das ruas, com um afluxo de escravos e estrangeiros que abalou o ideal de civilidade almejado por uma elite romana influenciada pela cultura helênica. Na Europa das grandes navegações, surgiram as metrópoles coloniais, centros urbanos em que as riquezas do Novo Mundo e do Oriente evocavam intensas trocas e encontros: populacionais, financeiros, culturais etc. Foi nesse período que começou a constituir-se o conceito mesmo de metrópole e sua associação com o cosmopolitismo, como sede das vanguardas, como encontro de raças e de línguas, de riqueza e de pobreza, do novo e do inesperado. Já na urbanização pós-industrial, com características parecidas ao redor do mundo, e que no Brasil traduziu-se na emergência da cidade como centro de oferta de serviços, cada vez menos dependente das fábricas. Foi a própria expansão da cidade, seu mercado imobiliário, que passou a alimentar a economia. Foi um período de grandes obras de infraestrutura urbana e de êxodo rural. Surgiram os centros metropolitanos, decorrentes tanto das necessidades habitacionais dos que chegavam quanto do aumento vertiginoso do preço da terra urbana e a consequente expulsão dos pobres do centro em direção à periferia. Estes centros metropolitanos caracterizam-se por constituírem enormes conurbações, grandes aglomerados de cidades menores, cidades dormitórios, de personalidade apagada, cidades de natureza genérica, que se agregam a uma cidade maior, com mais personalidade e com características mais definidas.

Nessa dinâmica que estabelece: ora uma ordenação e uma organização da urbanidade segundo um ideal transcendente, ora uma liberação dos fluxos, uma expansão desordenada e imprevisível da cidade, desvincula-se os termos capital e metrópole dos entes geográficos que eles evocam e passa-se a tomá-los por relação ao princípio de organização que eles determinam. "A metrópole é como uma membrana que permite a comunicação entre dois ou mais meios, enquanto a capital serve como núcleo em torno do qual estes meios são rigorosamente organizados" (Querrien apud Landa, 2000, p. 50). Se, por um lado, temos o princípio da metrópole que é o dos encontros contingenciais, espontâneos, autoperformativos, que criam seu estatuto e suas regras no próprio ato, seguindo as leis da rua, que faz comunicarem-se dois ou mais meios sem uma centralidade organizadora; por outro lado temos o princípio da capital que é uma norma de segurança, de classificação, de gerenciamento, de imposição de uma normatização desde uma instância exterior que determina a melhor forma de ocupação do espaço, que o ordena "rigorosamente" ao redor de núcleos. Assim como a metrópole não designa mais apenas os centros mercantis da época dos descobrimentos, isto é, a metrópole imperial por oposição à cidade colonial; a capital tampouco designa apenas a sede do governo, mas uma razão ordenadora do espaço urbano que busca acima de tudo uma funcionalidade, uma estabilidade. O princípio que subjaz ao modo capital de organização urbana é o da segurança. A constituição de um espaço seguro, previsível, sem riscos nem solavancos, sem conflitos, é isto que está em jogo na capital. Num certo sentido, a ideia da capital como lógica de organização preventiva das cidades faz ressonância com a 
proposição de Foucault (1978/2008) acerca do paradigma da segurança aplicado ao espaço urbano:

Em primeiro lugar, abrir eixos que atravessassem a cidade e ruas largas o bastante para assegurar quatro funções. Primeira a higiene, o arejamento, eliminar todas aquelas espécies de bolsões em que se acumulavam os miasmas mórbidos nos bairros demasiado apertados, em que moradias eram demasiado apinhadas. Função de higiene, por tanto. Segunda, garantir o comércio interior da cidade. Terceira, articular essa rede de ruas com estradas externas de modo que as mercadorias de fora pudessem chegar ou ser enviadas, mas isso sem abandonar as necessidades do controle aduaneiro. E, por fim - o que era um dos problemas importantes das cidades do século XVIII -, possibilitar a vigilância, a partir do momento em que a supressão das muralhas, tornada necessária pelo desenvolvimento econômico, fazia que não fosse mais possível fechar a cidade de noite ou vigiar com rigor as idas e vindas durante o dia [...]. Em outras palavras, tratava-se de organizar a circulação, de eliminar o que era perigoso nela... (p. 24)

Não há expressões puras da capital ou da metrópole, mas, frequentemente, um país tem duas grandes cidades nas quais em cada uma predomina um tipo de organização - a metrópole e a capital. Nos EUA, Nova Iorque e Washington. No Brasil, Rio de Janeiro e Brasília. Na Espanha, Barcelona e Madrid. Na China, Hong Kong e Pequim. A hipótese que gostaria de lançar, entretanto, é a de que há um movimento de capitalização das cidades, isto é, de ordenação urbana seguindo a lógica da capital, mesmo naquelas cidades que historicamente comportam-se como metrópole. Em outras palavras, há uma Brasília insurgindo-se dentro do Rio de Janeiro e Brasil afora, quiçá pelo mundo.

Certas políticas como a Tolerância Zero em Nova Iorque e o Choque de Ordem no Rio de Janeiro são exacerbações desse princípio. São tentativas embora já vinculadas ao marketing político, às seduções eleitoreiras - de reforçar um funcionamento à moda da capital em cidades cuja dinâmica aquecida e veloz, faz com frequência dispararem devires de metrópole. Como característica em comum, tais políticas trazem a ideia de que as grandes manifesta- ções urbanas perigosas e violentas, o tráfico, o crime, o vandalismo, têm sua origem em práticas cotidianas e de menor monta. Assim, baseiam-se na ideia de que é ao não tolerar o menor desvio - desde uma briga de escola até uma bicicleta amarrada em local impróprio - ao impor, portanto, uma ordem rigorosa nem que seja por meio do choque, da força, da arbitrariedade, que se pode impedir que a cidade torna-se um caos não administrável. Tal como a noção de classes perigosas, ou de categorias desviantes (Lages e Silva \& Silva, 2008), essas políticas urbanas, seja de caráter explícito e declarado como nos casos citados, seja na sua forma sub-reptícia e naturalizada que é mais frequente, fazem apelo a um paradigma preventivo, isto é, buscam antecipar-se a uma desestabilização potencial que seria engendrada silenciosamente no corpo da cidade.

O Brasil viu emergir em 2013, como caixa de ressonância de eventos ocorridos em 2011 em Barcelona (Plaza Cataluña) e Madrid (Plaza del Sol), assim como do movimento Occupy Wall Street em Nova Iorque (Zuccotti Park) e já em 2013 em Istanbul (Parque Taksim Gezi) nas mobilizações contra a destruição de um parque para construção imobiliária, uma paixão metropolitana de experimentação da rua, de caráter extremamente heterogêneo, que vem produzindo consequências até o presente momento. Certamente tais consequências se refletem nos acontecimentos político-governamentais que não são objeto deste texto, mas refletem-se também em mentalidades, fazendo reverberar com intensidade a demanda por segurança, demanda por proteção, demanda por uma evitação da diferença, demanda para que a lei seja cada vez mais dura com aquilo que se refere aos modos de vida capazes de perturbar a paz do cidadão comum. Poderíamos dizer que aquilo que se destaca seja uma demanda para que as cidades funcionem sob o princípio da capital, diríamos com Landa (2000), ou capitalístico, diríamos com Guattari (1981) sobre os perigosos fluxos metropolitanos que se produzem na combustão espontânea da presença popular nas ruas.

O que parece ter surgido em 2013 é a emergência de uma expressão multitudinal de resistência expressa desta forma por Lages e Silva \& Baptista (2014):

Essa redução da cidade a um objeto e espaço de consumo, articulada com a sua tomada como problema de vigilância e gerenciamento, fala também de um modo de pensar e de existir no 
contemporâneo que tem nas recentes manifestações que se espalharam pelo Brasil em junho de 2013 um forte elemento de resistência. Tomando este conceito em sua acepção tal como pensada por Foucault a resistência não seria um levantar-se contra algo. Ontologicamente primeira, a resistência nos ajuda a formular a pergunta nos seus devidos termos. Não se trata de perguntar: por que as pessoas saíram à rua em multidão? A partir de Foucault, podemos perguntar, dado que a resistência seria o exercício da liberdade como a qualidade primeira da nossa existência: por que não estamos sempre em multidão? O que nos tira da rua e nos interioriza em certos espaços disciplinares? Ou ainda, o que não precisa nos tirar da rua para nos interiorizar? (p. 26).

O que tudo isso tem a ver com a Psicologia Social? Como as diferentes Psicologias Sociais teriam vivido esse momento?

Para percorrer essas interrogações proponho um trabalho de imaginação.

\section{Exercício ficcional}

No presente exercício textual ou narrativo, convido os leitores a imaginarem que a "Psicologia Social" pudesse se corporificar como um cidadão. Um habitante das nossas cidades, um sujeito médio, ordinário. Desses que transitam ou deambulam pelas ruas e que veem a cidade todos os dias. Melhor do que "a" Psicologia Social, digamos que "as" nossas psicologias sociais pudessem ser convertidas ou encarnarem-se em diferentes tipos psicossociais (Deleuze \& Guattari, 1992). Seriam, então, como as pessoas que habitam as nossas cidades e que agregam um número suficiente de características ou qualidades que juntas compõem o que chamamos de um tipo.

São, nesse sentido, certas formas caricatas e estereotipadas que só servem para nos fazer ver aquilo que nas velocidades cambiantes da nossa subjetividade e do mundo, às vezes nos escapa.

Nosso exercício constitui-se, pois, em colocar essas nossas psicologias sociais antropomorfizadas numa situação em que os seus modos de transitar e de ver sejam perturbados e em que elas precisem ser menos usuárias ou passageiras da experiência urbana e mais agentes, mais autora, mais produtoras, de modo que seu modo de agir possa ser problematizado.
A situação proposta são as jornadas de junho de 2013, que levaram muitas pessoas, e por diferentes razões, às ruas no Brasil. Como as nossas psicologias sociais teriam ido a esses eventos caso pudessem serem pensadas como tipos psicossociais? Em especial, vamos atentar para quais concepções de direitos humanos e de políticas públicas subjazem a cada maneira de habitar a cidade, já que nem a dimensão humana dos direitos e nem a dimensão pública das políticas são autoevidentes. Ao contrário, trata-se de objetos de investimentos que ganham distintas conotações, nos diferentes encontros performados entre sujeitos e mundos.

A primeira Psicologia Social convertida em tipo psicossocial que vamos colocar em trânsito durante as jornadas de junho tem a característica de pensar a cidade como apartada das forças coletivas que a compõe. Para ela a cidade apresenta-se como um mero sistema material e concreto, como simples suporte físico para as condutas humanas. Falo de uma Psicologia Social que ainda existe e que pensa a cidade como um mero lócus de interações individuais. Ou seja, uma Psicologia que toma o indivíduo como o invólucro da subjetividade. Um indivíduo para o qual a cidade é apenas um palco onde ele estabelece a sua sociabilidade.

De tradição cientificista e inspiração no que Robert Farr (2008) chamou de Psicologia Social Psicológica, essa Psicologia Social foi a primeira a ganhar força no Brasil e o fez a partir das pesquisas e publicações de Aroldo Rodrigues (1979). Iniciativas mais contemporâneas buscam compor essa abordagem do meio social com os processos de pensamento ou tomada de decisões, resultando em abordagens ditas cognitivistas sociais ou sociocognitivistas (Bandura, Azzi, \& Polydoro, 2008; Dweck \& Legget, 1988), as quais, em que pese não agreguem semelhanças suficientes para constituírem uma escola, têm em comum via de regra uma concepção que separa o social como a fonte de "estímulos externos" ou dimensão de efetuação das condutas, e o indivíduo como a interioridade que processa tais informações e estímulos de forma mais ou menos enviesada por aspectos emocionais ou adaptativos.

Essa Psicologia Social, no seu olhar para a cidade, vai geralmente se preocupar em entender coisas como: o comportamento no trânsito; o comportamento do consumidor; a percepção social; os estereótipos sociais e outras temáticas similares. 
Essa Psicologia Social entende que a cidade é tão somente o espaço no qual o sujeito expressa aquilo que está no seu interior. A cidade aqui tem uma concepção quase negativa, no sentido de que ela não faz funcionar nada, ela não coloca nada em movimento, ela não produz. Ela apenas serve de suporte a uma produção que é centrada no homem, mais especificamente, no indivíduo. Tudo iniciaria na interioridade dos indivíduos e a cidade seria simplesmente o espaço para o qual essas necessidades, esses discursos, essas emoções, essas cognições ou essas percepções seriam dirigidos. Obviamente, essa Psicologia vai remeter o tema da discriminação, por exemplo, ao campo dos processos perceptivos e/ou cognitivos. Então se há discriminação, isso se deve ao processo natural e adaptativo de estranhamento da diferença, nada teria a ver com os processos históricos de estigmatização e de opressão. A discriminação seria apenas o efeito psíquico decorrente do fato adaptativo, evolutivo, de que os grupos competem entre si. A violência no trânsito, outro exemplo, seria tão somente uma potencialização de uma competitividade intrínseca à espécie e que se apresenta sob a forma da tentativa de se impor através do carro; do carro maior, mais caro, mais veloz etc.

Essa Psicologia que renega a cidade como um espaço político, que desconhece a potência perturbadora da urbe, que compreende a cidade como um simples suporte para a expressão das individualidades, logicamente não consegue compreender que os movimentos sociais, e podemos pegar o exemplo das jornadas de junho, são movimentos que falam em nome de um direito à cidade. Um exercício político, portanto, uma reclamação de que direitos humanos não podem vir dissociados dos direitos políticos.

Esse psicólogo, quando inserido em uma política pública, vai falar em nome do sujeito liberal, consumidor de direitos; do sujeito que reclama seus direitos ao Estado; do sujeito que compreende que o Estado lhe deve, pois lhe toma seus impostos. É a Psicologia que interpreta a relação entre os cidadãos e o Estado como uma relação mercadológica de demanda versus oferta.

Nas jornadas de junho essa Psicologia foi às ruas para reclamar da corrupção. A corrupção é o corolário dos efeitos perniciosos da vida coletiva sobre o indivíduo. O cidadão deixa de fruir individualmente do bônus amealhado pelo seu trabalho, paga impostos em nome de um bem coletivo que nunca chega porque o corrupto o desvia. O liberalista costuma usar a corrupção para falar em nome do fracasso da coletividade.

Essa Psicologia foi às ruas também para pedir segurança. Aqui a cidade é uma imensa fonte de problemas porque ela não cessa de drenar os recursos do indivíduo. O policiamento, a pavimentação, a iluminação, a saúde etc. Para essa Psicologia a cidade é um grande passivo no livro caixa dos indivíduos.

Possivelmente ela foi às ruas com um cartaz dizendo que "o Gigante acordou". Não é de espantar, porque essa Psicologia tem ojeriza à palavra "povo". E está acostumada a reduzir o múltiplo à unidade.

O segundo exemplo é o da Psicologia social que toma os movimentos sociais como um bem em si, como uma substância apartada das cidades, das políticas públicas e dos direitos humanos. Temos nos acostumado a chamá-la de Psicologia Social engajada ou militante e, em que pese sua importância histórica na construção de uma Psicologia Social de caráter crítico, ela parece desconhecer o papel desempenhado pela Psicologia enquanto prática individualizante e normatizadora (Rose, 2011), numa individualização e normatização que não se dão em oposição à autonomia dos sujeitos mas em articulação a esta.

Em geral, essa Psicologia que se resume a ser militante e perde de vista um caráter analítico e problematizador está sobreimplicada (Lourau, 1990) com o seu objeto de identificação e fecha trincheiras no seu grupo, formando aquilo que Guattari (1981) chamou de grupelho, ou seja, algumas formações identitárias de grupo que costumam ocorrer principalmente dentro das organizações de minorias, sejam elas raciais, de gênero, de diversidade sexual, etc., as quais se organizam antagonicamente a outros grupos de interesse.

Forjada na esteira das iniciativas críticas empreendidas por Martin-Baró (1997) e pelo movimento de contestação do paradigma positivista e cientificista reinante na Psicologia Social da América Latina e que acabou culminando com a formação da Associação Brasileira de Psicologia Social, essa Psicologia Social remodelou o dispositivo da "pesquisa-ação" proposto por Lewin (1965) sob a inspiração da dialética materialista-histórica (Lane, 1984) e construiu uma Psicologia Social e social-comunitária fortemente calcadas no dispositivo grupal enquanto espaço de identificações horizontais e de "desalienação". Falando 
em nome de uma igualdade e uma justiça abstratas, a serem conquistadas "de baixo para cima" através das lutas sociais, mas sonhadas de "cima para baixo" a partir das utopias burguesas, esta Psicologia social desconhece que a busca de uma sociedade igualitária se dá pelo encontro e pela experimentação da diferença e não pela eliminação destas.

Frequentemente, essa Psicologia Social vai defender aqueles com os quais ela se identifica, mesmo "contra" outras minorias. Para ela, quando feminista, tudo começa com a discriminação de gênero, que seria, por sua vez, mais importante e relevante que a discriminação de classe, por exemplo. Ou que tudo começa com a discriminação do louco e que a discriminação de gênero é menos violenta, ou opressora, e assim por diante.

Excluindo a dimensão da cidade e a perspectiva heterogenética que ela nos aporta, os movimentos sociais enclausuram-se em suas próprias identidades e passam a reclamar direitos humanos enquanto objetivos estratégicos. Para eles os direitos humanos não são o plano de um exercício ético, mas o espólio de uma competição entre grupos. Então quando um governo sensível a sua causa ascende ao poder, o psicólogo que atua nessa Psicologia Social é o primeiro a formar parte do governo, porque ele entende que finalmente surgiu a chance de fazer algo prático e de causar benefícios reais e produzir resultados positivos ao seu grupo. E mesmo que esse governo persiga outras minorias ou negue direitos aos outros movimentos sociais que não o seu, esse psicólogo não entra em contradição porque ele entende que está fazendo a sua parte. Para esse psicólogo, as políticas públicas são objeto de uma disputa. Uma disputa de recursos, de verbas, enfim, da atenção do Estado para com os seus correligionários. O caráter público das políticas que ele reclama fica em segundo lugar, pois ele transforma toda a política pública numa vantagem estratégica para o seu segmento.

Essa Psicologia Social também foi às jornadas de junho; e foi carregando suas bandeiras. E foi tão aparamentada com camisetas, cartazes e palavras de ordem, que não conseguiu perceber as outras pessoas. Ao seu redor havia apenas companheiros de luta. Na sua concepção o mundo está dividido entre aqueles que pensam igual a si, e os que pensam diferente e precisam ser convencidos. Em suma, ela foi às ruas em junho para dar o seu recado e não para ouvir o que os outros movimentos tinham a dizer.
Outra Psicologia Social que esteve nas ruas em 2013 foi aquela que separa os direitos humanos de seu contexto urbano, coletivo, político e cotidiano A Psicologia Social que encarna essa disjunção é aquela que empresta seu "saber" de especialista sobre o ser humano para justificar a construção de leis protetivas e humanizadoras. Os psicólogos que atuam nessa Psicologia Social são, em geral, militantes dos direitos humanos e compreendem tais humanos dignos de direitos como entidades idealizadas que estão sempre no horizonte da história, e nunca no chão do presente. Essa Psicologia Social, extremamente racionalista e otimista com os processos de modernização, acredita que a humanidade vem caminhando desde a pré-história, de uma condição primitiva, inumana e injusta, para o progresso em direção à razão e ao bem-estar universal. Tudo é apenas uma questão de tempo e uma questão de conquistarmos instrumentos jurídicos que garantam direitos aos que se encontram vulneráveis. Essa Psicologia quer leis progressistas, leis de adoção homoafetiva, leis de criminalização da homofobia, de legalização da maconha, de desmilitarização das polícias etc. Mas não quer fazer o debate sobre a intolerância sexual, a violência do Estado ou a criminalização da pobreza. Essa Psicologia entende os direitos humanos como regras de um jogo e não como formas de luta. Ela não percebe que os direitos humanos são experimentados na vida urbana e que são frutos de um embate permanente dos movimentos sociais frente à tentativa de privatizar o Estado e transformá-lo num espectador neutro da competição entre os indivíduos.

As políticas públicas, nessa concepção desvitalizada de direitos humanos, são o objeto de um gerenciamento e buscam adaptar-se às regras do jogo, ao politicamente correto, aos programas, planos e sistemas que os planejadores inventam desde os seus gabinetes, tão inquestionáveis em sua razão progressista, e ao mesmo tempo tão dissociados do cotidiano dos atores sociais.

Essa Psicologia Social arraigada ao sonho do progresso e da modernização social foi às jornadas de junho com cartazes pedindo a legalização da maconha, mas não se sentiu bem quando acenderam um baseado ao seu lado. Ela pedia a criminalização da homofobia, mas se incomodou quando viu um casal gay se beijando na sua frente. Ela pedia a desmilitarização das polícias, mas entendeu que a culpa da violência nas manifestações era, primeiro 
de tudo, dos Black Blocks. Essa Psicologia Social voltou cedo para casa. As jornadas de junho tinham um caráter indeterminado, indócil, potencialmente selvagem, que a atemorizou.

A última Psicologia Social que gostaria de levar às ruas é aquela que pensa as políticas públicas como um conjunto de práticas que não se relaciona com a cidade. A Psicologia que desconhece o histórico de conquistas dos movimentos sociais que estão na base da construção das políticas públicas e que seguem tensionando o seu presente. Os psicólogos que dão sustentação para essa Psicologia se consideram operadores de políticas públicas e, frequentemente, naturalizam o objetivo da sua prática. Se eles atendem no CAPS, por exemplo, eles entendem que seu trabalho é meramente técnico e que nada tem a ver com a luta antimanicomial; se são matriciadores na atenção básica, sentem-se mais como supervisores do que como colegas; via de regra, posicionam-se mais como um controle de qualidade do SUS, do que como militantes pela saúde pública de qualidade. Se trabalham na socioeducação, sentem-se mais como operadores do sistema de justiça, na pior hipótese, da segurança pública, do que como promotores dos direitos da criança e do adolescente.

A Psicologia Social que é protagonizada por estes psicólogos não se interessa pela cidade. Para ela a cidade é o conjunto dos territórios abrangidos pela sua política. A cidade é o zoneamento, a territorialização, nunca a uma fonte de incertezas, nunca a desterritorialização, nunca uma "lâmina fria cortando cômodas suposições" como no poema de Sebastião Uchoa Neto (apud Gomes, 2008). A cidade para essa Psicologia é o que nos prende, não o que nos tira o chão.

O trabalho do psicólogo nas políticas públicas, quando descolado dessa dimensão perturbadora da cidade que é, propriamente, a sua dimensão pública, a sua dimensão política, a dimensão onde o encontro com a diferença nos faz outro, nos coloca em devir, nos inquieta; o trabalho $p s i$ sem essa potência da diferença torna-se facilmente capturado pelos regimes de urgência que caracterizam a percepção privatista da política. No regime de urgência estamos sempre lidando com as exigências pragmáticas e imediatas e submetemos a nossa práxis à tirania de kronos, do tempo calculável, do tempo do capital, relegando o tempo da experiência, o tempo do encontro, o tempo da criação a uma protelação sem fim; a um tempo que nunca chega. Aqui, os direitos humanos são vis- tos como excelentes ideias, porém irrealizáveis. Como aquilo que deveria ser, mas que nunca é. Com um otimismo que a dureza da realidade não cessa de acusar de ingênuo, os psicólogos que se deixam tomar por essa modulação da Psicologia Social podem chegar a se ressentir com os direitos humanos. A mera lembrança da sua existência soa como uma acusação. A consciência dolorosa de que fomos esquecendo os nossos sonhos de juventude.

A verdade é que o trabalho em políticas públicas, quando apartado do caráter político que a cidade, os movimentos sociais e os direitos humanos trazem, nos envelhece rapidamente. Antes de percebermos já estamos desqualificando os inconformados como idealistas. Apesar disso, essa Psicologia não deixou de ir às jornadas de junho. Ela saiu às ruas para demandar uma política pública "padrão FIFA". Mas, o curioso, é que fazia essa demanda sem ironia. Essa Psicologia realmente acreditava que as políticas públicas deveriam se oferecer aos cidadãos ao modo individualizante e asséptico das novas arenas do futebol. Como se a cosmética individualizante do capital fosse capaz de resgatar a alegria que a ética de estar juntos um dia nos trazia.

Essas quatro imagens que eu estou propondo, e que gosto de pensar não existirem de modo puro no mundo real, são-nos, entretanto, muito familiares. Elas são como espectros, como fantasmas que assombram as nossas teorias e práticas em Psicologia Social.

Acontecimentos como a saída da população às ruas, como vem ocorrendo desde 2011 na Espanha e na Grécia, passando pela Primavera Árabe, movimento Occupy e as jornadas de junho no Brasil e na Turquia não se deixam interpretar no tempo curto e, via de regra, só podem ser melhor lidos no desenrolar da história longa.

Temos vivido, porém, desde 2013 e ainda hoje, os efeitos de uma tensão viva de um campo de forças atravessado por múltiplos vetores, tais como: a conquista de direito pelas minorias; a judicialização das relações sociais; a reação dos setores detentores do capital financeiro; da pequena-burguesia que convive mal com a ascensão dos mais pobres; enfim, um campo complexo e que ainda não mostrou como vai se resolver. Porém, a Psicologia Social frente a esse momento crucial encontra na ação de levar às ruas seus saberes e práticas uma alternativa muito mais interessante do que o isolamento no academicismo ou no pragmatismo governamental. 


\section{Clamor das ruas}

Em 2014 nos reunimos no encontro da ABRAPSO_ Sul em Londrina ainda fortemente impactados pelos eventos do ano anterior. Como a Psicologia escutaria isso que as ruas gritavam? Por isso o título do evento: "O clamor das ruas".

Sem a pretensão de dar conta dessa pergunta, teço algumas reflexões sobre os lugares de onde podemos escutar esses gritos.

Algumas abordagens podem entender esse grito como um pedido de tutela. As ruas querem algo, vamos ajudá-las; vamos dar o que se pede; vamos aplacar esse clamor. Também podemos tomar essa insatisfação como uma acusação: vamos nos defender; vamos nos justificar; vamos nos explicar as nossas razões. Podemos escutar esse grito como uma palavra de ordem. As ruas denunciam. Falam uma verdade que queríamos esquecer. Vamos então capitular. Vamos nos deixar convencer. Vamos nos juntar a esse coro.

Ou então, e essa é a maneira através da qual eu gostaria de encaminhar essa reflexão, podemos entender esse "Clamor das ruas", como um grito de um animal silvestre que não pede nada, que desconhece o dono ou o adestrador. Ele apenas experimenta a sua voz. Ele é tal qual a cantiga de Sorocô, no conto de Guimarães Rosa (2005), elegíaco, contagiante, perturbador. A pedra que estilhaça a vidraça do apartamento burguês e salva os jovens da asfixia no filme "Os Sonhadores", do Bertollucci (2003). O clamor das ruas é mais um rumor do que uma narrativa. O fundo permanente de incompreensão e de irracionalidade que nos redime de nós mesmos e de todas as violências que praticamos em nome de conservar nossa virtude.

O que nos espanta no "Clamor das ruas" não é que ele nos convoca para um exterior, mas que ele nos rouba a esperança de interioridade. Espanta o sonho da pureza. Nos recorda de que não estamos isolados na cabine do trem e nem transitando georeferenciados pelo mapa de GPS do mundo.

É nesse sentido, pois, que a cidade comparece como o modo (e não o lócus) privilegiado através do qual se encontram e se compõem, no contemporâneo, os fluxos de gente, de concretude, de ideias, de linguagem, as tediosas trajetórias repetitivas e as regozijantes invenções, os estímulos e as coações, a velocidade e o engarrafamento, as incitações e as interrupções. Ela conjuga sem sintetizar o campo do pensamento com o das sensações. Ela não cessa de perturbar e horrorizar, mas também de seduzir e de encantar aos seus habitantes, produzindo com eles arranjos bastardos e inadmissíveis. $\mathrm{O}$ piedoso pede mais punição à bandidagem. $\mathrm{O}$ boêmio se protege em condomínios fechados. O mendigo se conecta na inter-rede. $\mathrm{O}$ artista vende propaganda. $\mathrm{O}$ vendedor inventa poemas. O poeta escreve cidades imaginárias etc... A cidade interroga a todo instante as nossas identidades e o que pretendemos no mundo. $\mathrm{O}$ urbano, em seu devir de metrópole, devassa nossas pretensas individualidades com as errâncias da multidão e confronta a idealizada precedência do homem na natureza com a vitalidade dos entes inorgânicos, tecnológicos, maquínicos ou artificiais. A cidade não se deixa constranger pelos ideais (capitalísticos) de beleza e funcionalidade das nossas cidadanias privatistas. Ela afirma-se como objeto-experiência que traz consigo suas próprias condições de possibilidade. Não responde a um finalismo transcendente. Não serve para nada e não se encaixa numa linearidade causal (a cidade existe como decorrência disso...). Apresenta-se como fato contingencial, para além da díade acaso-necessidade.

Estamos numa relação de coengendramento com o urbano em que perder o olhar (paralaxe) e perder-se no espaço (devir, derivar) são forças constituintes da nossa existência. As ruas não são, pois, o elemento externo para o qual dirigimos o olhar e nem o trilho por onde deslocamos nossos corpos. Elas são como o motor do trem, uma fonte de vitalidade e movimento, cujo clamor é equivalente aos estalidos do trilho ou das vidraças que tilintam durante o movimento do vagão. Tal como os barulhos do trem interrompem a ficção de distância do passageiro. O grito das ruas interpela nossa relação de usuariedade com a cidade e nos incita para o exercício do comum.

\section{Referências}

Almeida, L. P. (2012). Para uma caracterização da psicologia social brasileira. Psicologia Ciência e Profissão, 32(esp), 124-137. https://doi.org/10.1590/S1414-98932012000500009

Bandura, A., Azzi, R. G., \& Polydoro, S. (2008). Teoria social cognitiva: Conceitos básicos. Porto Alegre, RS: Artmed. 
Bertollucci, B. (Diretor e Produtor). (2003). Os sonhadores (DVD). Paris: Fox.

Calcanhotto, A. (2002). Esquadros. São Paulo, SP: Tiranossaurus.

Certeau, M. (1994). A invenção do cotidiano: Artes de fazer. Petrópolis, RJ: Vozes.

Deleuze, G., \& Guattari, F. (1992). O que é a filosofia?. São Paulo, SP: 34.

Dweck, C. S., \& Leggett, E. L. (1988). A social-cognitive approach to motivation and personality. Psychological Review, 95(2), 256-273. https://doi.org/10.1037/0033-295X.95.2.256

Farr, R. (2008). As raízes da psicologia social moderna. Petrópolis, RJ: Vozes.

Foucault, M. (2008). Segurança, território e população. São Paulo, SP: Martins Fontes. (Obra original publicada em 1978).

Foucault, M. (1979). A governamentalidade. In M. Foucault, Microsfísica do poder (pp. 277-293). Rio de Janeiro, RJ: Graal.

Gomes, R. C. (2008). Todas as cidades, a cidade: Literatura e experiência urbana. Rio de Janeiro, RJ: Rocco.

Guattari, F. (1981). Somos todos grupelhos. In F. Guattari, Revolução molecular (pp. 12-19). Rio de Janeiro, RJ: Braziliense.

Lages e Silva, R. e, \& Silva, R. N. da. (2008). Paradigma preventivo e lógica identitária nas abordagens sobre o Hip Hop. Fractal: Revista de Psicologia, 20(1), 135-148. https://dx.doi.org/10.1590/S1984-02922008000100015

Lages e Silva, R., Baptista, L. A. S. (2014). Primavera urbana: A ilha deserta interroga as multidões. Psicologia \& Sociedade, 26(esp), 25-35. https://doi.org/10.1590/S0102-71822014000500004

Landa, M. (2000). A thousand years of non linear history. New York, NY: Swerve.

Lane, S. (1984). Consciência/alienação: A ideologia no nível individual. In S. Lane, \& W. Codo (Orgs.), Psicologia social: O homem em movimento. São Paulo, SP: Braziliense.

Lewin, K. (1965). Teoria do campo em ciência social. São Paulo, SP: Pioneira.

Lourau, R. (1990). Implication et surimplication. Revue du MAUSS, (10).

Martin-Baró, I. (1997). O papel do psicólogo. Estudos de Psicologia (Natal), 2(1), 7-27 https://doi.org/10.1590/ S1413-294X1997000100002

Pignatari, D. (1995). Semioticidade. In D. Pignatari, Letras, artes, mídia. São Paulo, SP: Globo.

Rodrigues, A. (1979). Estudos em psicologia social. Petrópolis, RJ: Vozes.

Rosa, G. (2005). Sorocô, sua mãe e sua filha. In G. Rosa, Primeiras estórias. Rio de Janeiro, RJ: Nova Fronteira.

Rose, N. (2011). Inventando nossos selfs. Petrópolis, RJ: Vozes.

\section{Rodrigo Lages e Silva}

Psicólogo. Doutor em Psicologia: estudos da subjetividade. Mestre em Psicologia Social e Institucional. Professor na Faculdade de Educação da Universidade Federal do Rio Grande do Sul (UFRGS), Porto Alegre - RS. Brasil.

E-mail: lagesesilva@gmail.com

(iD) https://orcid.org/0000-0002-6948-2824

Endereço para envio de correspondência:

Av. Paulo Gama, 110 - Sala 411. Farroupilha.

CEP: 90040-060. Porto Alegre - RS. Brasil.

Recebido 16/11/2017

Reformulado 02/08/2018

Aceito 17/09/2018 
Psicologia: Ciência e Profissão 2019 v. 39, e187957, 1-12.

Received 11/16/2017

Reformulated $08 / 02 / 2018$

Approved 09/17/2018

Recibido 16/11/2017

Reformulado 02/08/2018

Aceptado 17/09/2018

Como citar: Silva, R. L. (2019). Exercícios Ambulatórios para uma Reflexão acerca das Psicologias Sociais e da Cidade. Psicologia: Ciência e Profissão, 39, 1-12. https://doi.org/10.1590/1982-3703003187957

How to cite: Silva, R. L. (2019). Ambulatory Exercises for a Reflection upon Social Psychologies and the City. Psicologia: Ciência e Profissão, 39, 1-12. https:// doi.org/10.1590/1982-3703003187957

Cómo citar: Silva, R. L. (2019). Ejercicios Ambulatorios para una Reflexión acerca de las Psicologías Sociales y Urbanas. Psicologia: Ciência e Profissão, 39, 1-12. https://doi.org/10.1590/1982-3703003187957 